\title{
Role of Oxidative Stress in the Suppression of Immune Responses in Peripheral Blood Mononuclear Cells Exposed to Combustible Tobacco Product Preparation
}

\author{
Subhashini Arimilli ${ }^{10,4}$ Eckhardt Schmidt, ${ }^{2}$ Brad E. Damratoski, ${ }^{3}$ and G. L. Prasad ${ }^{2}$
}

\begin{abstract}
Cigarette smoking is a major risk factor for several human diseases. Chronic inflammation, resulting from increased oxidative stress, has been suggested as a mechanism that contributes to the increased susceptibility of smokers to cancer and microbial infections. We have previously shown that whole-smoke conditioned medium (WS-CM) and total particulate matter (TPM) prepared from Kentucky 3R4F reference cigarettes [collectively called as combustible tobacco product preparations (TPPs)] potently suppressed agonist-stimulated cytokine secretion and target cell killing in peripheral blood mononuclear cells (PBMCs). Here we have investigated the role of oxidative stress from TPPs, which alters inflammatory responses in vitro. Particularly, we investigated the mechanisms of WS-CM-induced suppression of select cytokine secretions in Toll-like receptor (TLR) agonist-stimulated cells and target cell killing by effector cells in PBMCs. Pretreatment with $N$-acetyl cysteine (NAC), a precursor of reduced glutathione and an established anti-oxidant, protected against DNA damage and cytotoxicity caused by exposure to WS-CM. Similarly, secretion of tumor necrosis factor (TNF), interleukin (IL)-6, and IL-8 in response to TLR-4 stimulation was restored by pretreatment with NAC. Target cell killing, a functional measure of cytolytic cells in PBMCs, is suppressed by WS-CM. Pretreatment with NAC restored the target cell killing
\end{abstract}

\footnotetext{
${ }^{1}$ Department of Microbiology \& Immunology, Wake Forest University Health Sciences, Room 2N-052, 575 Patterson Avenue, Winston-Salem, NC 27101, USA

${ }^{2}$ RAI Services Company, Winston-Salem, NC, USA

${ }^{3}$ Department of Regenerative Medicine, Wake Forest University Health Sciences, Winston-Salem, NC, USA

${ }^{4}$ To whom correspondence should be addressed at Department of Microbiology \& Immunology, Wake Forest University Health Sciences, Room 2N-052, 575 Patterson Avenue, Winston-Salem, NC 27101, USA. Email: sarimill@wakehealth.edu
}

Abbreviations, 7AAD, 7-Aminoactinomycin D; CBA, Cytometric Bead Array; CFSE, Carboxyfluorescein succinimidyl ester; CSE, Cigarette smoke extract; ELISA, Enzyme-linked immunosorbent assay; IFN, Interferon; IL, Interleukin; LPS, Lipopolysaccharide; NAC, $N$-Acetylcysteine; NK, Natural killer; PBMCs, Peripheral blood mononuclear cells; ROS, Reactive oxygen species; TLR, Toll-like receptor; TPM, Total particulate matter; TPPs, Tobacco product preparations; TNF, Tumor necrosis factor; WS-CM, whole-smoke conditioned medium 
in WS-CM treated PBMCs. This was accompanied by higher perforin levels in the effector cell populations. Collectively, these data suggest that reducing oxidative stress caused by cigarette smoke components restores select immune responses in this ex vivo model.

KEY WORDS: tobacco product preparations; $N$-acetylcysteine; PBMCs; LPS; cytotoxicity; cytokines; cytolysis.

\section{INTRODUCTION}

Cigarette smoking is a major risk factor for serious diseases such as cancer, chronic obstructive pulmonary disease (COPD), and cardiovascular diseases [1]. Cigarette smoke is a free radical-rich aerosol that contains thousands of chemicals, which can be partitioned into gas-vapor phase and particulate phases [2]. One of the mechanisms through which cigarette smoke exerts its adverse effects is through reactive oxygen species (ROS) present in smoke, which cause oxidative stress and induce local and systemic inflammatory responses [3]. Previous studies have suggested that exposure to cigarette smoke leads to an increased susceptibility to infections by influenza virus and Mycobacterium tuberculosis and significant changes in cellular immune responses $[4,5]$.

Given the complexity of cigarette smoke aerosol, several different preparations/fractions of cigarette smoke were utilized in different in vitro models to elucidate the mechanism of the adverse pathophysiological effects due to smoking [6]. For example, freshly generated smoke is bubbled through aqueous buffers/cell culture media to generate cigarette smoke extracts (CSE), which we have termed whole-smoke conditioned media (WS-CM); these preparations primarily contain water-soluble carbonyls, including acrolein, acetaldehyde, formaldehyde, 1,3 butadiene, ammonia, and nicotine. The particulate phase of cigarette smoke is collected on Cambridge filter pads and dissolved in dimethyl sulfoxide (DMSO), and is termed total particulate matter (TPM). Nicotine, tobacco-specific nitrosamines, organic amines, and other toxicants make up TPM. Direct treatment of cells with either TPM or WS-CM offers a simpler and yet useful approach than complex approaches that employ direct exposure of cells using airliquid interphase systems, and have been extensively utilized [7]. We have collectively referred to WS-CM, TPM, and other preparations from reference tobacco products (such as 3R4F and 2S3 moist snuff) as tobacco product preparations (TPPs) [8].

Previously we and others showed in cell culture systems that the combustible TPPs including WS-CM and TPM were more cytotoxic and genotoxic than noncombustible TPPs [8-10]. Lipopolysaccharide (LPS), an endotoxin in the membranes of gram-negative bacteria, binds to Toll-like receptor (TLR)-4 of the cell and effectively activates immune responses by inducing expression of proinflammatory cytokines [11]. TLR-stimulated inflammatory responses such as cytokine expression and secretion were significantly reduced upon treatment with the aqueous extract of cigarette smoke (CSE and WS-CM) [12-14].

Constituents of combustible TPPs have been shown to be potent pro-oxidants, which perturb the balance of intracellular pro- and anti-oxidants and consequently impact several biological pathways including inflammation [15]. Oxidants/reactive oxygen species (ROS) found in cigarette smoke are major contributors in mediating an inflammatory state in the pathogenesis of diseases such as COPD and lung cancer [16]. In vitro studies with primary T cells exposed to CSE which is a ROS source have revealed the induction of $\mathrm{T}$ cell apoptosis and decreased $\mathrm{T}$ cell proliferation [17].

Previous studies have shown that $N$-acetylcysteine (NAC) produced immunomodulatory effects through its actions as a scavenger of superoxide radicals and ROS [18-22]. Deacetylation of NAC yields L-cysteine, which is a precursor to glutathione synthesis. Glutathione is an intracellular anti-oxidant, and plays a major role in protecting cells against oxidative stress and DNA damage $[18,23]$. Treatment with NAC was shown to reverse cigarette smoke-induced myocardial infarction by inhibiting inflammation and oxidative stress in a rat model [24] and prevented lung tumors in mice [25]. Furthermore, NAC possesses anti-inflammatory properties [26] and has been suggested as a potential treatment option for cancer and prevent genetic mutations from occurring via reducing the role of reactive oxidative species in inducing mutations [23].

We have previously shown that TPM and WS-CM cause a dose-dependent increase in DNA damage and cell death and a dose-dependent reduction in secreted cytokines, intracellular cytokines, and cytolysis in PBMCs [8, 12]. Here we investigated the role of oxidative stress caused by combustible TPPs in suppression of immune functions and how one can restore select immunosuppression by reducing oxidative stress in an ex vivo model. 


\section{MATERIALS AND METHODS}

\section{TPPs and Cytotoxicity Measurement}

WS-CM and TPM were prepared from 3R4F cigarettes as described previously [8]. Partial characterization of WS-CM was performed at Labstat International, Kitchener, Canada, and it included analyses of several known toxicants of cigarette smoke (Table 1). Cytotoxicity was measured after exposing PBMCs to various concentrations of WS-CM or TPM for 3 or $24 \mathrm{~h}$ and staining the exposed cells with 7-aminoactinomycin D (7AAD), which labels dead cells. 7AAD-positive cells were measured by flow cytometry and analyzed by the FlowJo software (Tree Star, Ashland, OR) at various doses based on the equi-nicotine unit paradigm. The $\mathrm{EC}_{50}$ value of WS-CM and TPM was defined as the concentration at which $50 \%$ of the cells were no longer viable in a $24-\mathrm{h} 7 \mathrm{AAD}$ assay. The $\mathrm{EC}_{50}$ value of WS-CM and TPM was determined to be 1.56 and $2.58 \mu \mathrm{g} /$ $\mathrm{mL}$ of equi-nicotine units, respectively [8]. To measure the effect of NAC on the cytotoxicity, PBMCs were preincubated with and without $5 \mathrm{mM} \mathrm{NAC}$ for $1 \mathrm{~h}$ and subsequently exposed to different concentrations of WS$\mathrm{CM}$ plus $5 \mathrm{mM}$ NAC for $24 \mathrm{~h}$. PBMCs were washed and stained with 7AAD and measured by flow cytometry.

\section{PBMC Isolation and Stimulation}

PBMCs were isolated from fresh blood as described previously [27]. Isolated PBMCs were cryopreserved for further use. Cryopreserved PBMCs were thawed and then pre-incubated with and without $5 \mathrm{mM} \mathrm{NAC}$ for $1 \mathrm{~h}$ before exposure to different concentrations (equi-nicotine units)

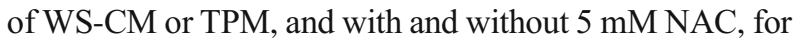
$3 \mathrm{~h}$ in RPMI 1640 media containing $10 \%$ fetal bovine serum with $1 \%$ L-glutamine, $1 \%$ penicillin, and streptomycin (RPMI complete medium). Cells were then washed and stimulated with $10 \mu \mathrm{g} / \mathrm{mL}$ LPS for $24 \mathrm{~h}$. After the 24-h stimulation, the cell culture supernatants were collected for analysis of secreted cytokines.

\section{Cytometric Bead Array Assay}

PBMC culture supernatants were analyzed using a Cytometric Bead Array (CBA) Human Inflammation kit or Th1/Th2 Human Cytokine kit (BD Biosciences, San Jose, CA) to measure interferon (IFN)- $\gamma$; tumor necrosis factor (TNF); and interleukin (IL)-1 $\beta$, IL-6, IL-8, and IL10 by flow cytometry according to the manufacturer's instructions.

\section{ELISA Assay}

Whenever the Th1/Th2 Human Cytokine kit was used, IL-8 was measured by enzyme-linked immunosorbent assay (ELISA) by using a kit from R\&D Systems (Minneapolis, MN) according to the manufacturer's protocol.

\section{Intracellular H2AX and Perforin Measurement}

PBMCs were pre-incubated with and without $5 \mathrm{mM}$ $\mathrm{NAC}$ for $1 \mathrm{~h}$ and subsequently exposed to different concentrations of WS-CM plus $5 \mathrm{mM}$ NAC for $24 \mathrm{~h}$. PBMCs were washed, fixed, and permeabilized with BD Biosciences Cytofix/Cytoperm buffer for $20 \mathrm{~min}$ on ice in the dark. Cells were then stained with ser-139 phosphorylated H2AX ( $\gamma$-H2AX-Alexa Fluor® 647, BD Biosciences) to measure DNA double-stranded breaks. To measure perforin levels, PBMCs were pre-incubated with and without $5 \mathrm{mM} \mathrm{NAC}$ for $1 \mathrm{~h}$ and subsequently exposed to different concentrations of WS-CM plus 5 mM NAC for $3 \mathrm{~h}$. PBMCs were washed, fixed, permeabilized, and stained with anti-perforin-fluorescein isothiocyanate monoclonal antibody for an additional $30 \mathrm{~min}$ on ice. Perforin-positive cells were measured by flow cytometric analysis, and the data were analyzed using the FlowJo software.

\section{Oxidative Stress Assay}

To measure oxidative stress, PBMCs were preincubated with and without $5 \mathrm{mM}$ NAC for $20 \mathrm{~h}$ and subsequently exposed to different concentrations of WS$\mathrm{CM}$ or TPM along with $5 \mathrm{mM}$ NAC for $1 \mathrm{~h}$ and labeled with the CellROX® Deep Red Reagent kit (Life Technologies, Grand Island, NY) according to the manufacturer's instructions. Pre-incubation of PBMCs with $5 \mathrm{mM}$ NAC for $1 \mathrm{~h}$ showed no effect on oxidative stress. CellROX reagent preferentially binds to superoxide and hydroxyl radicals, and is essentially non-fluorescent in a reduced state but exhibits a strong fluorogenic signal upon oxidation, thereby providing a reliable measure of ROS in live cells. The fluorescence was measured by flow cytometry, and the data were analyzed using the FlowJo software.

\section{Target Cell Killing Assay}

K562 target cells were purchased from ATCC (Manassas, VA) and grown in RPMI complete medium. K562 cells were labeled with carboxyfluorescein succinimidyl ester (CFSE). PBMCs were pre-incubated with and without $5 \mathrm{mM} \mathrm{NAC}$ and exposed to different concentrations of 
WS-CM for $3 \mathrm{~h}$; cells were washed and mixed with CFSElabeled K562 cells at a density of 100,000 cells/well (target/effector ratio 1:15). Cell co-cultures were incubated at $37^{\circ} \mathrm{C}$ for an additional $5 \mathrm{~h}$. Immediately after the incubation period, cells were stained with 7AAD and the killing of CFSE-labeled K562 target cells was evaluated by flow cytometry and the data were analyzed using the FlowJo software.

\section{Statistical Comparisons}

Results are presented as the mean \pm the standard error of the mean (four donor samples). Treated and control samples were compared using $t$ tests. The statistical significance was indicated by $* P<0.05$, $* * P<0.005$, and $* * * P<0.0005$.

\section{RESULTS}

Partial characterization of WS-CM was performed, and the mean and standard deviations of WS-CM tobacco constituents from three different batches were calculated and are presented in Table 1 . The mean value of nicotine was $9.2 \mu \mathrm{g} / \mathrm{mL}$, and from this value, the equi-nicotine units were calculated when different doses of WS-CM were used in the experiments. Tobacco-specific nitrosamines, nitrosonornicotine (NNN), nitrosoanatabine (NAT), and 4-(N-nitrosomethylamino)-1-(3-pyridyl)-1-butanone (NNK) were detected in WS-CM. Of these three compounds, NNK was detected at a higher level at $2470 \mathrm{pg} /$ $\mathrm{mL}$, followed by NNN at $1716 \mathrm{pg} / \mathrm{mL}$ and NAT at $1506 \mathrm{pg} /$ $\mathrm{mL}$. Carbonyl compounds known to be biologically reactive and contribute to ROS generation, such as aldehyde and ketone levels, are also measured in this panel, and their levels are indicated in Table 1. Several other constituents tested in this panel were shown to be below the detection limit (BDL).

To determine the degree of burden of oxidative stress induced by WS-CM or TPM, we used a CellROX assay that directly measures ROS in live cells. PBMCs were pretreated with NAC (or without) and exposed to increasing amounts of WS-CM or TPM. A dose-dependent increase in percent CellROX was observed with both WSCM and TPM. ROS levels, as measured by CellROX, were greatly reduced after the addition of NAC in a dosedependent manner, particularly at concentrations over $2 \mu \mathrm{g} / \mathrm{mL}$ WS-CM and TPM (expressed as equi-nicotine units) concentrations (Fig. 1). At a $5 \mu \mathrm{g} / \mathrm{mL}$ equi-nicotine unit of WS-CM, the amount of ROS detected without NAC
Table 1. Chemical Analysis of WS-CM

\begin{tabular}{|c|c|c|c|}
\hline Tobacco constituents of WS-CM & Units & Mean & $\mathrm{SD}$ \\
\hline Nicotine & $(\mu \mathrm{g} / \mathrm{mL})$ & 9.2 & 0.8 \\
\hline Nornicotine & $(\mu \mathrm{g} / \mathrm{mL})$ & BDL & - \\
\hline Anabasine & $(\mu \mathrm{g} / \mathrm{mL})$ & BDL & - \\
\hline Myosmine & $(\mu \mathrm{g} / \mathrm{mL})$ & BDL & - \\
\hline Anatabine & $(\mu \mathrm{g} / \mathrm{mL})$ & $\mathrm{BDL}$ & - \\
\hline Un-ionized nicotine & $(\mu \mathrm{g} / \mathrm{mL})$ & 4.48 & 0.7 \\
\hline Ammonia & $(\mu \mathrm{g} / \mathrm{mL})$ & 9.19 & 0.6 \\
\hline Nitrosonornicotine (NNN) & $(\mathrm{pg} / \mathrm{mL})$ & 1716 & 717 \\
\hline Nitrosoanatabine (NAT) & $(\mathrm{pg} / \mathrm{mL})$ & 1506 & 1145 \\
\hline Nitrosoanabasine (NAB) & $(\mathrm{pg} / \mathrm{mL})$ & 306 & 234 \\
\hline $\begin{array}{l}\text { 4-( } N \text {-nitrosomethylamino)-1- } \\
\text { (3-pyridyl)-1-butanone (NNK) }\end{array}$ & $(\mathrm{pg} / \mathrm{mL})$ & 2470 & 2013 \\
\hline NDMA & $(\mathrm{ng} / \mathrm{mL})$ & 2.45 & - \\
\hline NPIP & $(\mathrm{ng} / \mathrm{mL})$ & BDL & - \\
\hline NPYR & $(\mathrm{ng} / \mathrm{mL})$ & $\mathrm{BDL}$ & - \\
\hline NMOR & $(\mathrm{ng} / \mathrm{mL})$ & $\mathrm{BDL}$ & - \\
\hline Acrylamide & $(\mathrm{ng} / \mathrm{mL})$ & 28.5 & 2 \\
\hline Nitrite & $(\mu \mathrm{g} / \mathrm{mL})$ & BDL & - \\
\hline Ethyl carbamate & $(\mathrm{ng} / \mathrm{mL})$ & BDL & - \\
\hline$N$-nitrosodiethanolamine (NDELA) & $(\mathrm{ng} / \mathrm{mL})$ & NQ & - \\
\hline$N$-nitrosodiisopropanolamine (NDiPLA) & $(\mathrm{ng} / \mathrm{mL})$ & BDL & - \\
\hline$N$-nitrososarcosine & $(\mathrm{ng} / \mathrm{mL})$ & BDL & - \\
\hline Coumarin & $(\mathrm{ng} / \mathrm{mL})$ & 2.02 & 0.58 \\
\hline Formaldehyde & $(\mu \mathrm{g} / \mathrm{mL})$ & 0.621 & 0.07 \\
\hline Acetaldehyde & $(\mu \mathrm{g} / \mathrm{mL})$ & 73.6 & 1.27 \\
\hline Acetone & $(\mu \mathrm{g} / \mathrm{mL})$ & 34.9 & 0.62 \\
\hline Acrolein & $(\mu \mathrm{g} / \mathrm{mL})$ & 0.152 & 0.01 \\
\hline Propionaldehyde & $(\mu \mathrm{g} / \mathrm{mL})$ & 4.28 & 0.06 \\
\hline Crotonaldehyde & $(\mu \mathrm{g} / \mathrm{mL})$ & 1.28 & 0.05 \\
\hline Methyl ethyl ketone & $(\mu \mathrm{g} / \mathrm{mL})$ & 10 & 0.19 \\
\hline Butyraldehyde & $(\mu \mathrm{g} / \mathrm{mL})$ & 0.475 & 0.02 \\
\hline $\mathrm{pH}$ & (unit) & 7.99 & 0.06 \\
\hline Osmolarity & $(\mathrm{mOsm} / \mathrm{L})$ & 280 & 0.58 \\
\hline
\end{tabular}

was $44 \%$, but was lowered to $13 \%$ (statistically significant difference) in the presence of NAC (Fig. 1a). With TPM concentrations ranging from 0.5 to $4 \mu \mathrm{g} / \mathrm{mL}$, the amount of ROS in PBMCs that was decreased by addition of NAC was also statistically significant (Fig. 1b). With the TPM samples, there were statistically significant differences with the addition of NAC at the lower concentrations of TPM as compared with WS-CM at similar, equi-nicotine unit concentrations.

In our previous studies, we used different concentrations of WS-CM exposed to PBMCs at $3 \mathrm{~h}$ and showed that there is no significant cytotoxicity [28]. Hence we selected two concentrations of WS-CM to measure cytotoxicity and other endpoints in the current study and compared these results to the control. We assessed whether NAC-mediated reduction of ROS inhibits DNA damage and death of PBMCs caused by exposure to WS-CM. PBMCs were 

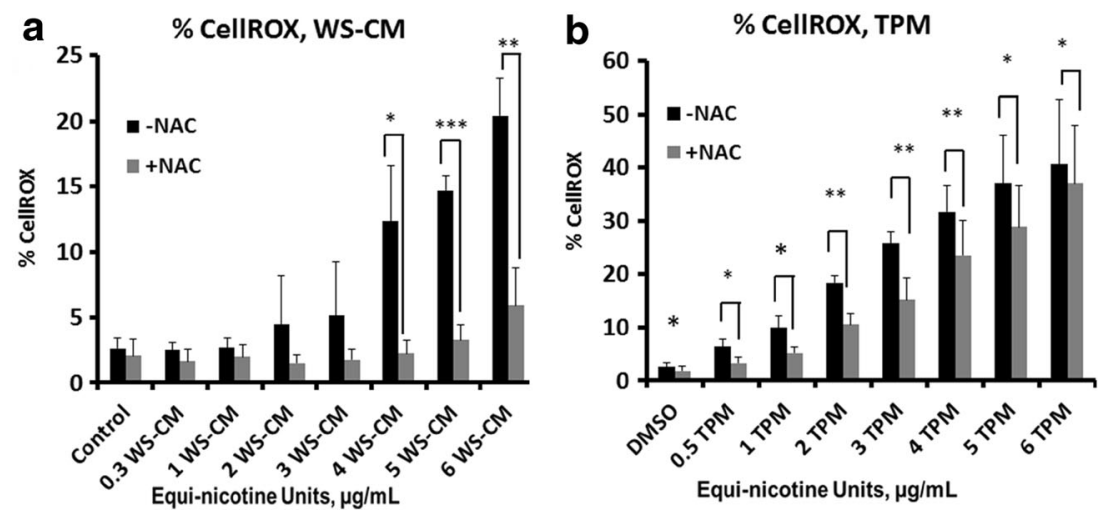

Fig. 1. Effects of NAC on oxidative stress in WS-CM- and TPM-exposed PBMCs. PBMCs were pretreated with or without NAC and followed by coincubation with different concentrations of WS-CM (a) or TPM (b). Oxidative stress was measured using a CellROX® kit and flow cytometry. Each point represents the mean $\pm \mathrm{SD}$ error bars of four donors from a representative experiment.

pretreated with or without NAC followed by co-incubation with WS-CM. We measured DNA damage by H2AX labeling and cell death by 7AAD labeling. The percent of H2AX-positive cells increased in a dose-dependent fashion with WS-CM treatment [8]. At $1.56 \mu \mathrm{g} / \mathrm{mL}$ WS-CM exposure, $20 \%$ cells were positive for $\mathrm{H} 2 \mathrm{AX}$; however, with the treatment of NAC, the percent of $\mathrm{H} 2 \mathrm{AX}$-positive cells was reduced to $8 \%$ (Fig. 2a). Similarly, the addition of NAC significantly decreased the number of dead PBMCs from 45 to $23 \%$ at $1.56 \mu \mathrm{g} / \mathrm{mL}$ WS-CM exposure (Fig. $2 \mathrm{~b}$ ).

Next we measured the levels of cytokines to assess whether NAC reverses the suppression of agonistmediated select inflammatory cytokine secretion in PBMCs. Cytokine levels of IL-8, TNF, and IL-6 were measured in PBMCs after pretreatment with or without NAC and subsequent co-incubation with WS-CM for $3 \mathrm{~h}$ followed by LPS stimulation. At a WS-CM concentration of $1.56 \mu \mathrm{g} / \mathrm{mL}$, three cytokines (IL-8, TNF, IL-6) were nearly undetectable without NAC treatment (Fig. 3a-c). However, the levels of all three cytokines were markedly increased in response to NAC treatment. After NAC treatment, IL-8 levels increased from 12 to $32 \mathrm{ng} / \mathrm{mL}$ and TNF levels increased from 1 to $38 \mathrm{ng} / \mathrm{mL}$ (Fig. 3a, b), whereas IL-6 levels increased to $200 \mathrm{ng} / \mathrm{mL}$ compared with the control condition (Fig. 3c). These findings show a recovery toward control cytokine levels with the addition of NAC, which was particularly evident with IL-6. Cytolytic function was measured to test the effects of WS-CM on the effector PBMCs to kill K562 cells in vitro, with and without NAC. Figure 4 a shows the raw data of flow cytometric analysis of K562 cell killing. Cell populations in each dot plot are gated, and the numbers within the gated boxes indicate the percent of K562 cells killed by the effector cells in PBMCs. There is a reduction in K562 cell killing from 18 to $5 \%$ at $1.56 \mu \mathrm{g} / \mathrm{mL}$ WS-CM without NAC (Fig. 4a, top panel) and with NAC inclusion percent of K562 cell killing recovered to that of unexposed control condition (Fig. 4a, bottom panel). The combined data show that without NAC pretreatment, K562 cell killing decreased from 14 to $6 \%$ with addition of $1.56 \mu \mathrm{g} / \mathrm{mL}$ WS$\mathrm{CM}$, whereas K562 cell killing was significantly recovered to control levels with NAC treatment in PBMCs exposed to $1.56 \mu \mathrm{g} / \mathrm{mL}$ WS-CM (Fig. $4 \mathrm{~b}$ ).

We measured perforin-positive PBMCs after exposure to WS-CM in the presence and absence of NAC. Perforin is a protease that mediates cytolytic function of (NK) cells and cytotoxic T cells, and is a key enzyme in lysing target cells and thus is critical in regulating immune function. Perforin-positive cells decreased to $30 \%$ without NAC treatment compared with NAC treatment in PBMCs exposed to $1.56 \mu \mathrm{g} / \mathrm{mL}$ (Fig. 5). After pretreatment of PBMCs with NAC followed by co-incubation with $1.56 \mu \mathrm{g} / \mathrm{mL}$ WS-CM, perforin-positive cells recovered to the levels of the control condition (Fig. 5).

\section{DISCUSSION}

A previous work has indicated that cigarette smoking induces oxidative stress and inflammation $[15,16]$. Several researchers have shown that NAC can reduce inflammation in smokers and that NAC can be potentially used as a therapeutic agent for smoking-related diseases, including cancer and COPD [23, 26, 29, 30]. In this study, we demonstrate that oxidative stress caused by combustible TPPs (WS-CM or TPM) contributes to DNA damage, cell death, 

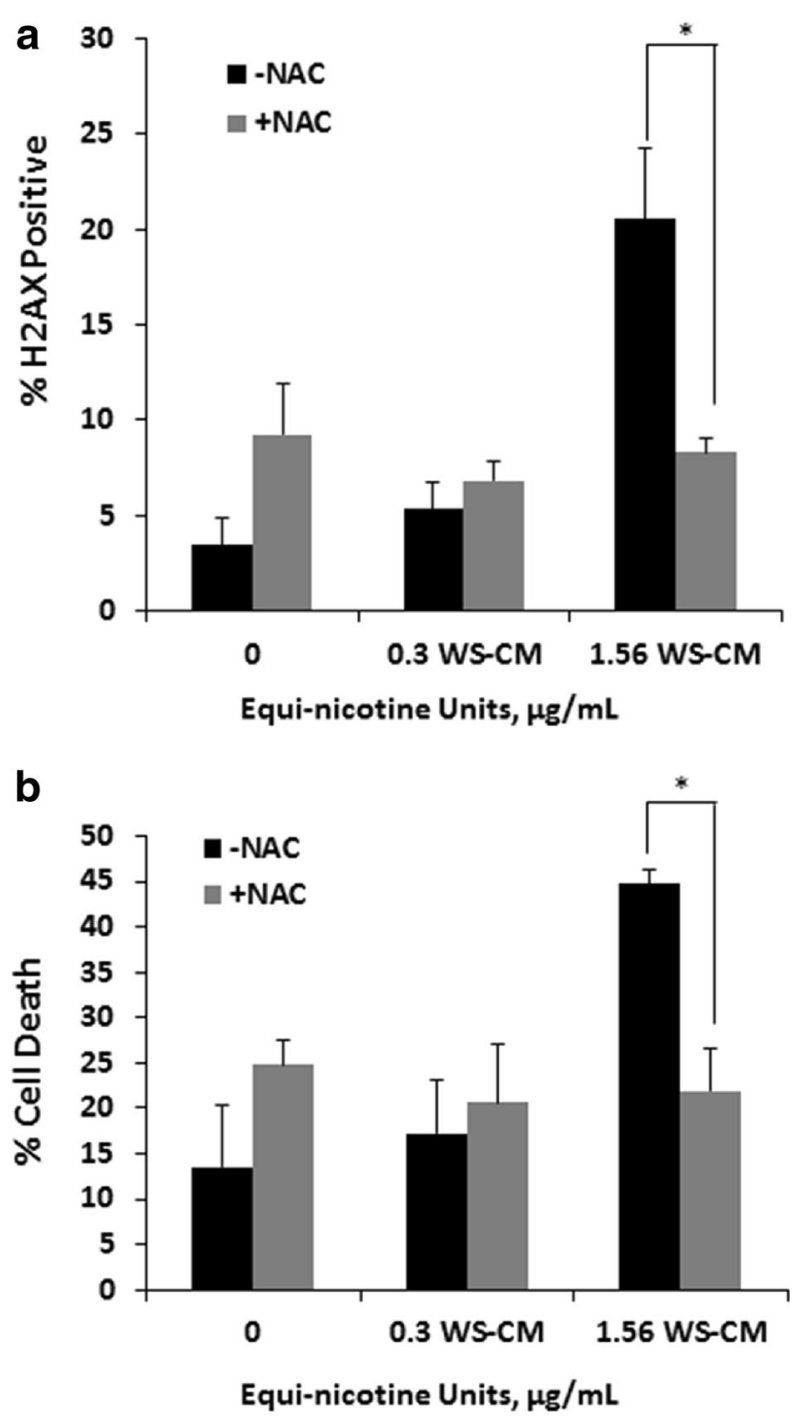

Fig. 2. Recovery of cytotoxic effects of WS-CM-exposed PBMCs pretreated with NAC. PBMCs were pretreated with or without NAC for $1 \mathrm{~h}$ followed by co-incubation with WS-CM for $24 \mathrm{~h}$. DNA damage was measured by H2AX staining using flow cytometry (a) and cell death was measured by 7AAD staining (b). Each point represents the mean $\pm \mathrm{SD}$ error bars. Data were derived from samples provided by four different donors; shown here are results from a representative experiment. $* P<0.05$

suppression of agonist-mediated select inflammatory cytokine secretion, and cytolytic functions of PBMCs in the ex vivo model. We showed that reducing oxidative stress by pretreatment with NAC results in improved cell viability, decreased DNA damage, and rescued cytokine secretion by TLR ligands and cytolytic functions in PBMCs.

Several studies have indicated greater levels of oxidative stress in cigarette smokers [31,32], which is most likely attributed to the high concentration of ROS and nitrogen species (RNS) in cigarette smoke [33-36]. In addition, cigarette smoke has been associated with elevated ROS production by leukocytes in the airways of both acute and chronic smokers [37]. Previous studies have examined the effects of cigarette smoke and NAC on specific immune functions in animal models $[24,25]$. NAC is effective in the inhibition of mutagenic properties of ROS [23] as well as modulating cytokine production and inflammation [21, 38]. Here, we measured a dose-dependent increase in ROS using PBMCs exposed to increasing concentrations of WS-CM and TPM, which was restored in the presence of NAC. We also measured a dose-dependent increase in levels of eNOS (nitric oxide synthase) with PBMCs exposed to increasing concentrations of TPM but not with WS-CM (unpublished results).

We have previously reported the dose-dependent increase in cell death and H2AX-positive cells with WS-CM- and TPM-exposed PBMCs [8]. In this study, our findings of increased H2AX-positive cells (increased DNA damage) and increased cell death after exposure to WS-CM added to the evidence that the oxidative stress is triggered by cigarette smoking [39, 40]. Here, we also demonstrated that NAC significantly reduces both DNA damage and cell death in PBMCs exposed to WS-CM.

TLR-stimulated inflammatory responses associated with cytokine expression and secretion were reduced significantly with the combustible TPPs [12-14]. Here we demonstrated that the levels of the cytokines TNF, IL-6, and IL-8 were significantly reduced after exposure to WS$\mathrm{CM}$ and recovered to the control levels in response to NAC treatment.

A functional measure of immune response is cytolysis or target cell killing. Cytolysis is a process which removes infected or cancerous cells with the help of NK cells and cytotoxic T cells. Previously, we and others demonstrated that WS-CM or cigarette smoke-conditioned medium reduces PBMCs and NK cell cytolytic activity $[12,41]$. Here we measured target cell killing of K562 cells by effector cells in PBMCs after treatment with WS-CM and showed how NAC significantly increased cytolysis.

Several lines of evidence suggest that NK cells and $\mathrm{CD} 8^{+}$cytotoxic $\mathrm{T}$ cells mediate cytolysis, which relies on perforin and granzyme-B, mainly by the granule exocytosis pathway in addition to a number of activating and inhibitory receptor-mediated pathways [42, 43]. Decreased cytolysis of NK cells and/or cytotoxic T lymphocytes is associated with reduced perforin expression [12, 41]. Here, we showed that perforin levels are reduced in PBMCs 

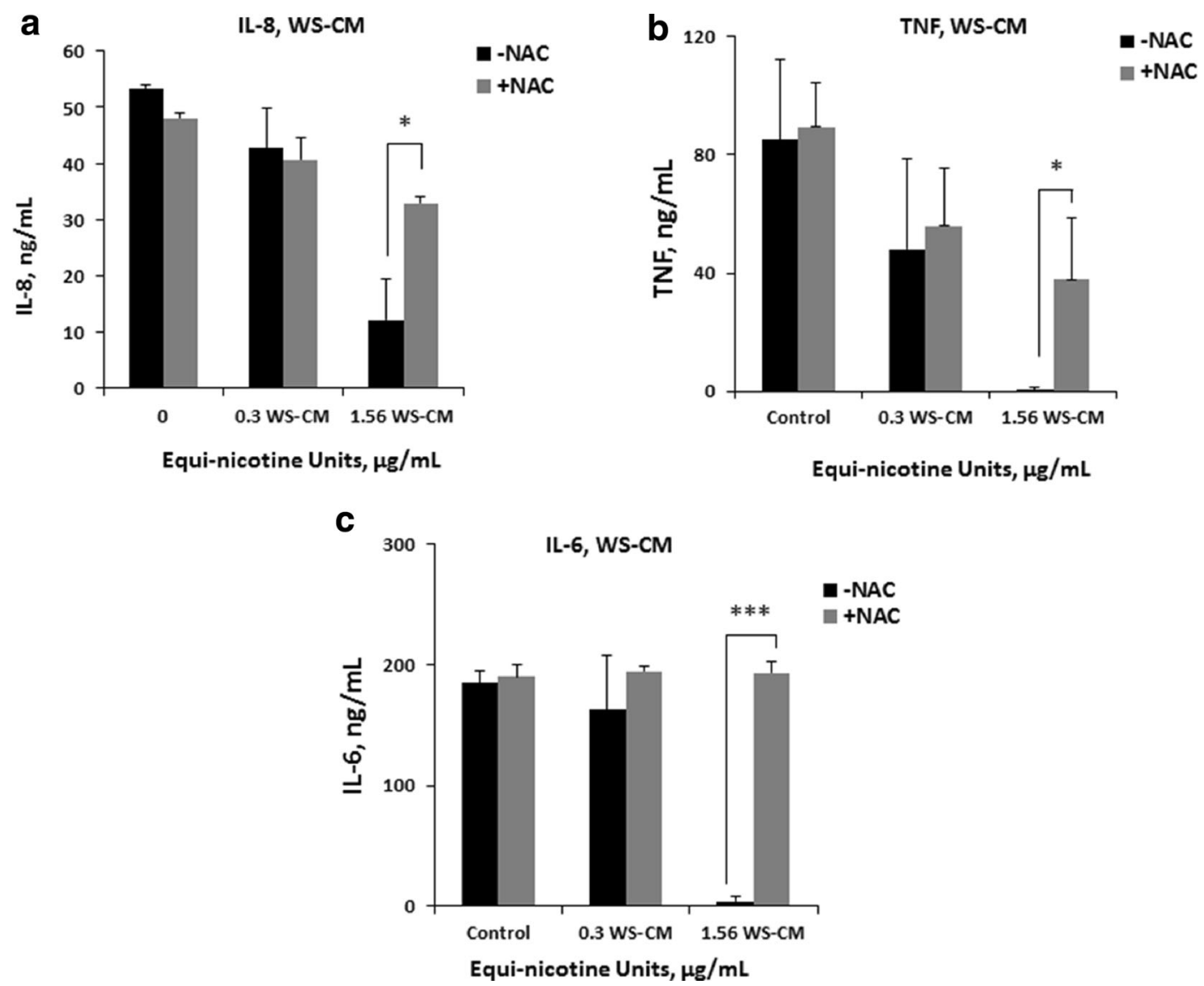

Fig. 3. Recovery in cytokine secretion of PBMCs with NAC after WS-CM exposure. PBMCs were treated with or without NAC for $1 \mathrm{~h}$ followed by coincubation with WS-CM for $3 \mathrm{~h}$ and LPS stimulation for $24 \mathrm{~h}$. Levels of IL-8 (a), TNF (b), and IL-6 (c) cytokines in the cell culture supernatants were obtained from PBMCs. Each point represents the mean \pm SD error bars of four donors from a representative experiment. Statistical significance is indicated by $* P<0.05 ; * * * P<0.0005$.

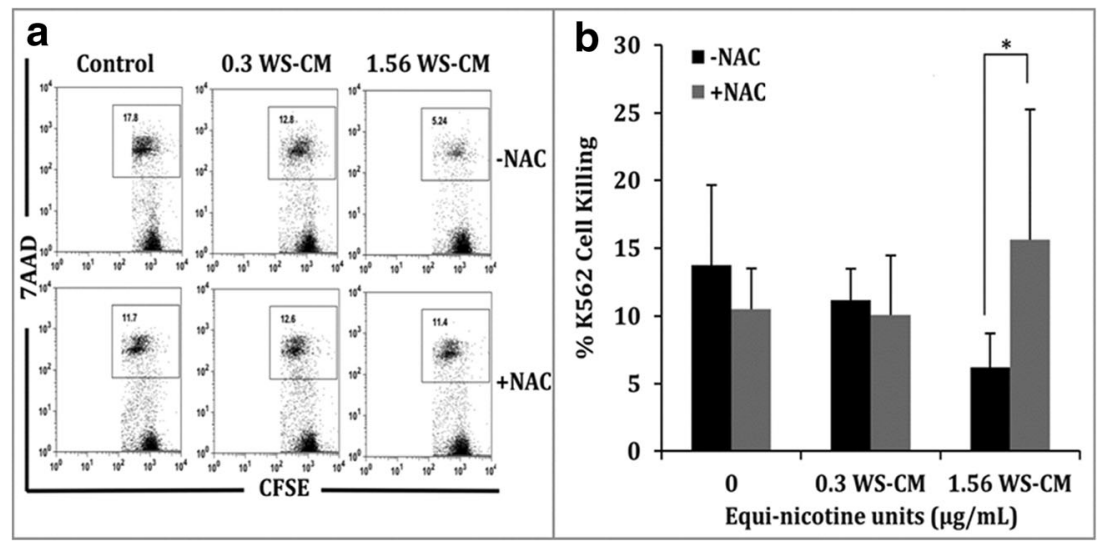

Fig. 4. Recovery in cytolysis of effector cell PBMCs with NAC after WS-CM treatment. PBMCs were exposed to indicate concentrations of WS-CM for $3 \mathrm{~h}$ with or without NAC. CFSE-labeled K562 cells were then added as target cells and incubated for an additional $5 \mathrm{~h}$. Cells were stained with 7AAD, and flow cytometry was used to gauge the killing of CFSE-labeled K562 cells. Flow cytometry data with percent of killing are shown in the gated boxes (a). Each point represents the mean $\pm \mathrm{SD}$ error bars of four PBMC donors (b). Statistical significance is indicated by $* P<0.05$. 


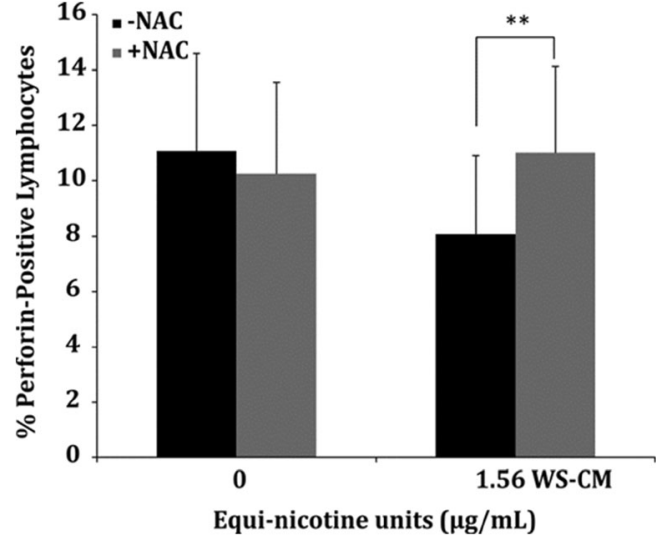

Fig. 5. Recovery of perforin-positive lymphocytes with NAC in WS-CMexposed PBMCs. PBMCs were treated with or without NAC for $1 \mathrm{~h}$ followed by co-incubation with WS-CM for $3 \mathrm{~h}$. Perforin levels were determined by cell staining and flow cytometry. The bar graphs are representative data from four different donor PBMCs. Statistical significance is indicated by $* * P<0.005$.

exposed to WS-CM, which was significantly reversed in the presence of an anti-oxidant.

\section{CONCLUSION}

Our data suggest that the oxidative stress caused by combustible TPPs suppressed immune responses in PBMCs as shown by change in levels of cytokines, cytolysis, and increased cytotoxicity. This immune suppression was restored by the addition of the anti-oxidant NAC. Additional work is necessary to define the molecular mechanisms involved in the restoration of oxidative stress and its role in immunomodulating the effects of combustible TPPs.

\section{ACKNOWLEDGEMENTS}

This work is funded by R.J. Reynolds Tobacco Company (RJRT) under a collaborative research agreement with Wake Forest University Health Sciences.

\section{COMPLIANCE WITH ETHICAL STANDARDS}

Conflict of Interest. G.L. Prasad and Eckhardt Schmidt are full-time employees of RAI Services Co. RAI Service Co and RJRT are operating companies of Reynolds American Inc. The authors declare that there are no conflicts of interest.
Open Access This article is distributed under the terms of the Creative Commons Attribution 4.0 International License (http://creativecommons.org/licenses/by/4.0/), which permits unrestricted use, distribution, and reproduction in any medium, provided you give appropriate credit to the original author(s) and the source, provide a link to the Creative Commons license, and indicate if changes were made.

\section{REFERENCES}

1. US Department of Health and Human Services. 2010. How tobacco smoke causes disease: the biology and behavioral basis for smoking-attributable disease, a report of the surgeon general. US Department of Health and Human Services, Centers for Disease Control and Prevention, National Center for Chronic Disease Prevention and Health Promotion, Office on Smoking and Health.

2. Perfetti, T.A. 2011. The complexity of tobacco and tobacco smoke. Beiträge zur Tabakforschung International 24 (5): 215-232.

3. van der Vaart, H., et al. 2004. Acute effects of cigarette smoke on inflammation and oxidative stress: a review. Thorax 59 (8): 713-721.

4. Mehta, H., K. Nazzal, and R.T. Sadikot. 2008. Cigarette smoking and innate immunity. Inflammation Research 57 (11): 497-503.

5. Feng, Y., et al. 2011. Exposure to cigarette smoke inhibits the pulmonary T-cell response to influenza virus and Mycobacterium tuberculosis. Infection and Immunity 79 (1): 229-237.

6. Johnson, M.D., et al. 2009. Evaluation of in vitro assays for assessing the toxicity of cigarette smoke and smokeless tobacco. Cancer Epidemiology, Biomarkers \& Prevention : a publication of the American Association for Cancer Research, cosponsored by the American Society of Preventive Oncology 18 (12): 3263-3304.

7. Fukano, Y., et al. 2004. Modified procedure of a direct in vitro exposure system for mammalian cells to whole cigarette smoke. Experimental and Toxicologic Pathology 55 (5): 317-323.

8. Arimilli, S., et al. 2012. Evaluation of cytotoxicity of different tobacco product preparations. Regulatory Toxicology and Pharmacology 64 (3): 350-360.

9. Lu, B., et al. 2007. Cytotoxicity and gene expression profiles in cell cultures exposed to whole smoke from three types of cigarettes. Toxicological Sciences 98 (2): 469-478.

10. Gao, H., G.L. Prasad, and W. Zacharias. 2013. Differential cellspecific cytotoxic responses of oral cavity cells to tobacco preparations. Toxicology In Vitro 27 (1): 282-291.

11. Ngkelo, A., et al. 2012. LPS induced inflammatory responses in human peripheral blood mononuclear cells is mediated through NOX4 and Gia dependent PI-3kinase signalling. Journal of Inflammation 9 (1): 1-1.

12. Arimilli, S., B.E. Damratoski, and G.L. Prasad. 2013. Combustible and non-combustible tobacco product preparations differentially regulate human peripheral blood mononuclear cell functions. Toxicology in Vitro : an international journal published in association with BIBRA 27 (6): 1992-2004.

13. Chen, H., et al. 2007. Tobacco smoking inhibits expression of proinflammatory cytokines and activation of IL-1R-associated kinase, p38, and NF-kappaB in alveolar macrophages stimulated with TLR2 and TLR4 agonists. Journal of Immunology 179 (9): 60976106. 
14. Goncalves, R.B., et al. 2011. Impact of smoking on inflammation: overview of molecular mechanisms. Inflammation Research 60 (5): 409-424.

15. Yao, H., and I. Rahman. 2011. Current concepts on oxidative/ carbonyl stress, inflammation and epigenetics in pathogenesis of chronic obstructive pulmonary disease. Toxicology and Applied Pharmacology 254 (2): 72-85.

16. Sundar, I.K., H. Yao, and I. Rahman. 2013. Oxidative stress and chromatin remodeling in chronic obstructive pulmonary disease and smoking-related diseases. Antioxidants \& Redox Signaling 18 (15): 1956-1971.

17. Hernandez, C.P., et al. 2013. Effects of cigarette smoke extract on primary activated T cells. Cellular Immunology 282 (1): 38-43.

18. Carnevali, S., et al. 2003. Cigarette smoke extract induces oxidative stress and apoptosis in human lung fibroblasts. American Journal of Physiology-Lung Cellular and Molecular Physiology 284 (6): L955-L963.

19. De Flora, S., et al. 1995. Mechanisms of anticarcinogenesis: the example of $\mathrm{N}$-acetylcysteine. In Drugs, diet and diseases. Mechanistic approach to cancer, ed. C. Ioannides and D. Lewis, 151-203. Hemel Hempstead: Horwood Ellis.

20. Groskreutz, D.J., et al. 2009. Cigarette smoke alters respiratory syncytial virus-induced apoptosis and replication. American Journal of Respiratory Cell and Molecular Biology 41 (2): 189-198.

21. Kar Mahapatra, S., et al. 2011. Alteration of immune functions and Th1/Th2 cytokine balance in nicotine-induced murine macrophages: immunomodulatory role of eugenol and $\mathrm{N}$-acetylcysteine. International Immunopharmacology 11 (4): 485-495.

22. Zafarullah, M., et al. 2003. Molecular mechanisms of Nacetylcysteine actions. Cellular and Molecular Life Sciences CMLS 60 (1): 6-20.

23. De Flora, S., et al. 2001. Mechanisms of N-acetylcysteine in the prevention of DNA damage and cancer, with special reference to smoking-related end-points. Carcinogenesis 22 (7): 999-1013.

24. Khanna, A.K., J. Xu, and M.R. Mehra. 2012. Antioxidant N-acetyl cysteine reverses cigarette smoke-induced myocardial infarction by inhibiting inflammation and oxidative stress in a rat model. Laboratory Investigation; a journal of technical methods and pathology 92 (2): 224-235

25. Balansky, R., et al. 2010. Prevention of cigarette smoke-induced lung tumors in mice by budesonide, phenethyl isothiocyanate, and $\mathrm{N}$ acetylcysteine. International Journal of Cancer 126 (5): 1047-1054.

26. Sadowska, A.M., Y.K.B. Manuel, and W.A. De Backer. 2007. Antioxidant and anti-inflammatory efficacy of NAC in the treatment of COPD: discordant in vitro and in vivo dose-effects: a review. Pulmonary Pharmacology \& Therapeutics 20 (1): 9-22.

27. Arimilli, S., et al. 2012. Rapid isolation of leukocyte subsets from fresh and cryopreserved peripheral blood mononuclear cells in clinical research. CryoLetters 33 (5): 376-384.
28. Arimilli, S., B.E. Damratoski, and L.P. G. 2015. Methods to evaluate cytotoxicity and immunosuppression of combustible tobacco product preparations. Journal of Visualized Experiments 95: 52351.

29. Kelly, G.S. 1998. Clinical applications of N-acetylcysteine. Alternative Medicine Review : a journal of clinical therapeutic 3 (2): 114 127.

30. Schmaal, L., et al. 2011. Efficacy of N-acetylcysteine in the treatment of nicotine dependence: a double-blind placebo-controlled pilot study. European Addiction Research 17 (4): 211-216.

31. MacNee, W. 2005. Oxidants and COPD. Current Drug Targets. Inflammation and Allergy 4 (6): 627-641.

32. MacNee, W. 2005. Pulmonary and systemic oxidant/antioxidant imbalance in chronic obstructive pulmonary disease. Proceedings of the American Thoracic Society 2 (1): 50-60.

33. Churg, A., M. Cosio, and J.L. Wright. 2008. Mechanisms of cigarette smoke-induced COPD: insights from animal models. American Journal of Physiology. Lung Cellular and Molecular Physiology 294 (4): L612-L631.

34. Puhakka, A., et al. 2003. High expression of nitric oxide synthases is a favorable prognostic sign in non-small cell lung carcinoma. APMIS 111 (12): 1137-1146.

35. Gaston, B., et al. 1994. The biology of nitrogen-oxides in the airways. American Journal of Respiratory and Critical Care Medicine 149 (2): 538-551.

36. Soini, Y., et al. 2000. Expression of inducible nitric oxide synthase in healthy pleura and in malignant mesothelioma. British Journal of Cancer 83 (7): 880-886.

37. Bowler, R.P., P.J. Barnes, and J.D. Crapo. 2004. The role of oxidative stress in chronic obstructive pulmonary disease. COPD 1 (2): 255-277.

38. Al-Shukaili, A., et al. 2009. Effect of N-acetyl-L-cysteine on cytokine production by human peripheral blood mononuclear cells. Sultan Qaboos University Medical Journal 9 (1): 70-74.

39. Asami, S., et al. 1997. Cigarette smoking induces an increase in oxidative DNA damage, 8-hydroxydeoxyguanosine, in a central site of the human lung. Carcinogenesis 18 (9): 1763-1766.

40. Albino, A.P., et al. 2004. Induction of H2AX phosphorylation in pulmonary cells by tobacco smoke: a new assay for carcinogens. Cell Cycle 3 (8): 1062-1068.

41. Mian, M.F., et al. 2008. Impairment of human NK cell cytotoxic activity and cytokine release by cigarette smoke. Journal of Leukocyte Biology 83 (3): 774-784.

42. Trapani, J.A., and M.J. Smyth. 2002. Functional significance of the perforin/granzyme cell death pathway. Nature Reviews. Immunology 2 (10): 735-747.

43. van Dommelen, S.L., et al. 2006. Perforin and granzymes have distinct roles in defensive immunity and immunopathology. Immunity 25 (5): 835-848. 